\title{
Los sentidos de la rendición de cuentas en el discurso educativo
}

\author{
Noelia Fernández-González, ${ }^{*}$ Héctor Monarca**
}

Perfiles Latinoamericanos, 26(51)

2018 | pp. 379-401

DOI: $10.18504 / \mathrm{pl} 2651-015-2018$

\begin{abstract}
Resumen
Las palabras pueden ser entendidas como sistemas o categorías que promueven significados sobre la realidad social y la construyen. Esto se evidencia con ciertos conceptos que se vuelven relevantes en determinados momentos y contextos. Este es el caso de rendición de cuentas, un término que al usarse en el campo educativo oculta las disputas simbólicas subyacentes sobre sus significados y las que tienen lugar en los sistemas que le dan existencia. Es por eso que en este texto se reflexiona acerca de los sentidos que dicho concepto asume en el discurso y en las políticas educativas, lo mismo que sobre sus efectos pedagógicos; se indaga además respecto de su aceptación y naturalización en el campo educativo.
\end{abstract}

\begin{abstract}
Words can be understood as systems or categories that promote meanings relating to social realities and contribute to their formation. This is particularly evident in the case of certain concepts or constructs that are especially relevant to precise instances and contexts, like accountability. The use of this term in the field of education conceals the symbolic disputes that underlie its meanings and the systems that give rise to its existence. This article reflects on the meanings of accountability in educational discourse and policies, and on their pedagogical effects. Similarly, their acceptance and naturalisation within the field of education are examined herein.
\end{abstract}

Palabras clave: rendición de cuentas, discurso educativo, política educativa, efectos pedagógicos, evaluaciones, neoliberalismo.

Keywords: Accountability, educational discourse, educational policy, pedagogical effects, assessment, neoliberalism.

* Máster en Educación por la Universidad Autónoma de Madrid (UAM). Personal docente e investigador en formación en el Departamento de Didáctica y Teoría de la Educación de la UAM | noelia.fernandezg@uam.es

** Doctor en Educación por la Universidad Complutense de Madrid. Profesor del Departamento de Didáctica y Teoría de la Educación de la UAM | hector.monarca@uam.es 


\section{Introducción}

n nuevo vocabulario se ha ido incorporando en las últimas décadas al discurso educativo: "transparencia", "calidad" y "rendición de cuentas" son ya palabras de uso común en los textos que norman la educación. Así se ha observado para el caso británico (Charlton, 2002), y basta con una somera lectura de las leyes estatales españolas en la actual etapa democrática para constatar la presencia creciente de dichos términos. De entre estos, únicamente el de “calidad" aparecía de modo fugaz en la Ley General de Educación de 1970, multiplicándose después en la Ley de Ordenación General del Sistema Educativo español (LOGSE) de 1990 y en las sucesivas leyes generales de educación. "Transparencia" y "rendición de cuentas" aparecen por primera vez en la Ley Orgánica de Educación (LOE) de 2006, asociadas principalmente al sistema de evaluaciones que esta ley implantaba. Este vocabulario se ha instalado plenamente en el texto de la última reforma: la Ley Orgánica para la Mejora de la Calidad Educativa (LOMCE) de 2013.

Tal y como comenta Puelles (2009), muchos de estos conceptos se trasladan al campo educativo desde el mundo de la empresa en la década de los ochenta y, desde entonces, no solo son moneda común en las leyes educativas y entre quienes diseñan las políticas, sino que de igual modo aparecen en medios de comunicación y son ampliamente empleados por ciudadanía, educadores, estudiantes, madres y padres. Se trata, sin embargo, de conceptos que son aprehendidos acríticamente y que merecen un examen a la luz de las prácticas educativas que naturalizan. Es preciso analizar cómo este vocabulario vehicula la incorporación de elementos de la ideología de mercado a la vida institucional y profesional, incluso a la vida cotidiana, y termina transformando las teorías, las concepciones y el sentido común sobre la educación. Lo primero que se debe destacar es que esta importación de conceptos económicos al ámbito educativo no es una casualidad en un momento en que la educación misma se está convirtiendo en mercancía (Ball \& Youdell, 2007; Dale, 2007; Robertson, Bonal \& Dale, 2007). Se trata de una colonización mediante la que, como explica Da Silva (1997), ciertas narrativas y representaciones "conquistan" las políticas y las prácticas educativas. Precisamente, Norman Fairclough (2000), desde el área de los estudios del discurso, constata esta colonización - aunque él habla de "recontextualización" - como una práctica habitual del discurso neoliberal. Así, además de la educación, la sanidad o el gobierno local se abordan desde discursos propios de la gestión, lo que a la postre supone el "sometimiento" de sus propias prácticas.

Este cambio en el discurso educativo debe interpretarse a la luz de la reconfiguración de la institución del Estado dentro del complejo proceso de globali- 
zación, el cual, entre otras muchas cosas, pone en disputa distintos modelos de Estado. Así, Cerny (1997) entiende como fenómeno central de la globalización el paso del Estado de bienestar al Estado competitivo, cuya esencia es favorecer los procesos de acumulación capitalista. Siendo este su objetivo prioritario, parece coherente el cambio discursivo. En consecuencia, las políticas públicas de este Estado competitivo vienen sobre todo inspiradas por un mandato de eficacia (Dale, 1999), que en materia educativa ha supuesto un viraje en el foco de atención, de los insumos a los resultados (Tröhler, 2009). Esta mayor preocupación por los resultados explica la tendencia global a implantar sistemas de evaluación, donde el Estado queda constituido, no ya como proveedor directo, sino como un Estado evaluador que garantiza la provisión educativa mediante entes públicos o privados indistintamente; y que mide sus resultados y estándares de calidad por medio de dispositivos diversos (Neave, 1988). Se pasa así de un modo de regulación burocrático propio del Estado keynesiano a otro de regulación posburocrático, tal como lo denomina Barroso (2005) y que Fraser (2003) identifica como una tendencia a "gobernar a distancia", donde los mecanismos de mercado operan de una manera preponderante.

La propuesta de la tercera vía de Anthony Giddens (1999), que popularizó la nueva gestión pública, asume esta misma lógica, ya que parte de la idea básica de organizar lo público de acuerdo a los principios del mundo privado. Supone, en consecuencia, una nueva imbricación entre el Estado y el mercado que rompe la antinomia entre ambos, propia de la etapa fordista (Burchardt, 2004). De esta forma, la disciplina de mercado se erige como la organizadora social. En este sentido, Domingues (2014) ve en esta nueva izquierda una "vía social liberal" que constituye una alternativa menos ortodoxa de los postulados neoliberales. Siendo esta la esencia de la tercera vía, y destacando que se trata de un discurso dirigido a reformar la socialdemocracia, merecería un espacio aparte el análisis de sus divergencias y convergencias con el discurso neoliberal, ya que ambas propuestas parecen descansar sobre una perspectiva inevitable de los cambios globales, sobre la exigencia de mayor competitividad como objetivo prioritario y sobre su fe en la lógica organizativa del mundo empresarial. En este sentido, desde un enfoque neomarxista, el neoliberalismo se ha visto como una suerte de tsunami económico conducido por fuerzas de mercado y que ataca a los Estados. Esta aproximación es lo que Ong (2007) cataloga como Neoliberalismo con "N" mayúscula. Sin embargo, la socióloga distingue además un neoliberalismo con " $n$ " minúscula que, desde enfoques foucaultianos, pone su foco de atención en cómo estas políticas introducen tecnologías de gobierno para conducir la conducta de los individuos. En este sentido, los mecanismos de la nueva gestión pública vinculados a la tercera vía constituyen tecnologías de gobierno que introducen lo que ya en los setenta Foucault 
(2007) denominó como gubernamentalidad neoliberal, y que se caracteriza por invitar a los individuos a comportarse como empresarios de sí mismos. Dentro de estas tecnologías de gobierno, las evaluaciones externas ocupan un lugar relevante (Ball, 2013; Carvalho, 2009; Monarca, 2015). Las mismas, aunque tienen una larga historia, cobran otros sentidos en el marco de estos nuevos modos de control y vigilancia.

En materia educativa, podemos confirmar para el caso español la confianza que comparten el Partido Socialista Obrero Español (PSOE), de tradición socialdemócrata, y el Partido Popular, de tradición conservadora, en las evaluaciones externas como mecanismos de rendición de cuentas. La LOE de 2006, impulsada por el PSOE introdujo las primeras evaluaciones externas como mecanismos de rendición de cuentas a nivel nacional. Sin embargo, es la última ley de educación, la LOMCE, aprobada por el Partido Popular en 2013, la que profundiza en esta dirección, otorgando un mayor protagonismo a las evaluaciones externas (Monarca, Fernández-González \& Sandoval, 2015): ha aumentado su número y ha regulado la publicación de sus resultados por centro escolar, naturalizando así el derecho a la libertad de elección por parte de las familias. Junto con esto, dota a las escuelas de mayor autonomía, lo que en los hechos se traduce en una "autonomía controlada". Se puede afirmar que los mecanismos de rendición de cuentas, articulados a través del tándem autonomía-evaluaciones externas, responden a la nueva racionalidad política global posfordista propia del neoliberalismo.

Las evaluaciones, como primera mitad de este tándem posburocrático, ilustran lo que Grek (2009) llama "la gobernanza de los números" o, en palabras más pesimistas, la "tiranía de los números" (Ball, 2015), y deben ser vistas como tecnologías propias de una cultura performativa (Ball, 2003), más vinculada a los mecanismos informativos del mercado, y que se vale de evaluaciones, comparaciones y otros indicadores para producir el cambio. El comportamiento de los actores es modelado por estas tecnologías de gobierno, apareciendo así nuevas subjetividades (Ball, 2013). Los centros escolares modifican sus estrategias organizativas de cara a las evaluaciones y los docentes se adaptan a lo que las pruebas exigen de ellos. De esta manera se generan nuevas fabricaciones: versiones de la organización y de la persona para adaptarse a esos resultados esperados (Ball, 2003). Un gobierno suave o a distancia, si bien no ordena rigurosamente cada paso del individuo, sí prefigura cuál debe ser su resultado. La paradoja reside en que, tratándose de un gobierno a distancia, sin embargo, se organiza de manera vertical y jerárquica: este es el significado de la gobernanza en el siglo xxi (Laval \& Dardot, 2013); incluso, en ocasiones, mucho más centralizado que los modelos burocráticos tradicionales. Por eso cabría decir que la organización posfordista no responde ya a la sociedad disciplinaria que Foucault observaba 
en la etapa fordista, en cambio, estaríamos asistiendo a la sociedad de control de la que nos hablaba Deleuze (2006).

En esta sociedad de control, la metáfora organizativa ha dejado de ser la fábrica, un espacio rígido donde se producen bienes, y ha pasado a ser la empresa, caracterizada por la flexibilidad y enfocada a la producción de conocimiento (Deleuze, 2006). Esta metáfora de la empresa asimismo llega a la organización educativa, que debe ser ahora más flexible que antes (Hargreaves, 1996) y, como la misma LOMCE aclara, debe responsabilizarse por sus resultados. La figura del director escolar queda configurada como la del gerente de la empresa-escuela (Merchán, 2012; Monarca, 2012; Monarca, Fernández-González \& Sandoval, 2015). Pero en última instancia, la metáfora empresarial alcanza el "alma del individuo", que debe verse como empresario de sí mismo tanto si es estudiante (Jódar \& Gómez, 2007) como docente (Ball, 2013). Los sujetos deben calcular y pensar su valor añadido en función de su desempeño. En este escenario, cada cual es el principal responsable de su devenir.

Nancy Fraser (2003) entiende que, en este paso de un mundo disciplinado a otro donde reina la flexibilidad, la gubernamentalidad opera combinando mecanismos de autorregulación y represión. Los sujetos autorregulados asumen la responsabilidad individual de sus actos y actúan tal y como los mecanismos posburocráticos imponen. En contrapartida, y de acuerdo con la autora, donde no hay una lógica de responsabilización, actúa una lógica de represión abierta, e incluso en ocasiones ilegal. En este sentido, el miedo constituye el otro organizador social (Laval \& Dardot, 2013; Monarca, 2015). Elementos como la inseguridad ciudadana y, en materia educativa, muy particularmente el desempleo y la precariedad, son movilizados en el discurso como escenarios a los que hay que temer.

Parece que la introyección de responsabilidad individual juega un papel clave en el nuevo escenario global, más organizado por los mecanismos de mercado. La centralidad de la responsabilidad como mecanismo de gubernamentalidad explica el auge de las políticas y las prácticas de rendición de cuentas. Considerando esto, ¿cómo es posible la aceptación generalizada de la rendición de cuentas? Esta es la pregunta a la que pretende responder este trabajo. Para ello, en primer lugar, se realiza un análisis de la rendición de cuentas como disputa de sentidos, junto con la reflexión sobre las políticas de rendición de cuentas en educación y sus consecuencias pedagógicas. En segundo, se explora el potencial de la rendición de cuentas como mecanismo para la mejora de la democracia, asunto abordado desde el área de la política comparada, y que quizás explique parte de su aceptación. Finalmente, a partir de los análisis anteriores, se intenta responder a la pregunta sobre la incorporación, uso y naturalización de la rendición de cuentas en el campo educativo, reflexionando sobre las posibilidades de su propia resignificación. 


\section{Las disputas de sentido en torno a la rendición de cuentas}

La literatura académica anglosajona ha sido prolífica en el estudio de la rendición de cuentas en el ámbito de la educación, abordando la cuestión desde distintos puntos de vista. La mayoría de estos se han enfocado en la influencia del discurso y de las políticas denominadas de rendición de cuentas sobre la identidad docente y la organización escolar (Ball, 2013, 2003; Charlton, 2002; Poulson, 1998), y en la relación de las familias con las escuelas (Biesta, 2004; Windle, 2009). Otros han buscado establecer clasificaciones de modelos de rendición de cuentas (McDonnell, 1994). También han surgido propuestas, como la de O'Neill (2013), quien ha tratado de definir lo que denomina "rendición de cuentas inteligente”, una forma de responsabilidad basada en valores. Asimismo, y debido al interés creciente de los gobiernos por los resultados de sus sistemas educativos, muchos estudios han indagado en los efectos de las evaluaciones externas como mecanismos de rendición de cuentas (Stobart, 2010; Supovitz, 2009); en tanto que algunos más se han ocupado de observar los modos diversos de resignificar el concepto de rendición de cuentas, tanto en el nivel más macro del diseño de políticas (Hopmann, 2008) como en los niveles más micro: las representaciones que profesorado (Mausethagen, 2013) y familias (Biesta, 2004) tienen de esta noción.

Hopmann (2008) ilustra los diversos modos de resignificar la noción de accountability en función de las tradiciones político-democráticas de cada país. Destaca que no haya una palabra común de traducción a otros idiomas. Por ejemplo, la Comisión Europea (2001) traduce el término como responsabilidad, pero a su vez existen "auditoría", "responsabilidad social" y, sobre todo, "rendición de cuentas", la traducción más literal (Olvera \& Isunza, 2004; Schedler, 2008). ${ }^{1}$ En palabras de Hopmann (2008), la "mentalidad constitucional" de cada país es lo que define en gran medida la manera en que este concepto es resignificado en cada lugar y trasladado a prácticas concretas. El autor ilustra esta tesis cuando constata las diferentes formas en que la noción de accountability se ha interpretado en los países nórdicos, en Alemania y Austria, y en Estados Unidos.

Al inicio de su artículo, Hopmann (2008) elabora una revisión teórica rastreando el origen del concepto de accountability en distintas áreas de conocimiento. En el campo económico, la rendición de cuentas se ha articulado como un medio a través del cual un proveedor o responsable multiplica sus resultados incentivando a sus subordinados, o forzándolos por otros medios,

1 En este trabajo emplearemos indistintamente accountability y rendición de cuentas. 
para que informen de su eficiencia, su calidad y sus resultados. Desde las teorías de la administración pública, y concretamente desde la nueva gestión pública, la rendición de cuentas es una herramienta clave que se emplea para que personas o instituciones cumplan con los objetivos fijados, centrándose en su responsabilidad para conseguirlo o, dicho de otra manera, en su culpa si fracasan, es decir, si los objetivos no son conseguidos. En otras teorías de la administración, dice el autor, se ha relacionado la rendición de cuentas con el concepto de "sociedad auditora", es decir, la extensión de la verificación cuantitativa, medible, a distintas áreas de la vida social. Algunos investigadores en educación y salud, sostiene Hoppman, valoran la rendición de cuentas como un movimiento revolucionario hacia una práctica basada en evidencias, ${ }^{2}$ es decir, en la presentación de datos para demostrar que se ha actuado con eficiencia, eficacia y profesionalidad. Desde teorías interaccionales y transaccionales, la rendición de cuentas se conceptualiza como una forma de explicar lo que se hace. Desde enfoques psicológicos, se ha abordado la rendición de cuentas como las formas personales de hacer frente a la responsabilidad en el marco de roles y funciones que se asumen. En su clasificación, Hopmann (2008) incluye el enfoque crítico desde el cual algunos investigadores sociales han entendido la accountability, y sobre todo su concepción dentro de la nueva gestión pública, como parte de una "revolución del cuasi-mercado" que trae categorías mercantiles al sector público. En su revisión, sin embargo, este autor concluye que tales perspectivas se entrelazan y, en términos generales, predomina un uso cuyo objeto es "hacer responsable a alguien", responsabilizarlo por lo que hace. Desde algunos marcos, como la nueva gestión pública, estos mecanismos de responsabilización son valorados positivamente por su contribución a la mayor eficiencia y eficacia. Desde interpretaciones críticas de corte foucaultiano, constituyen tecnologías de dominación, de vigilancia, de control (Ball, 2003, 2013; Deleuze, 2006; Poulson, 1998).

$\mathrm{Al}$ margen del enfoque teórico que destaque más en cada propuesta concreta, las prácticas de rendición de cuentas en materia educativa han venido asociadas predominantemente a sistemas de evaluación, de supervisión o de inspección. Supovitz (2009) afirma que las evaluaciones se utilizan para hacer

2 En cualquier caso, es necesario problematizar el concepto de evidencias, en el cual muchas veces subyace una visión positivista que entiende la evaluación como una prueba objetiva-natural que da cuenta de la realidad. En este sentido, son sistemas creados para ver la realidad desde unos prismas muy específicos, sobre todo cuantitativos: indicadores o resultados de pruebas, los cuales estarían dando una radiografía de la realidad. En consecuencia, desde esta concepción subyacente, el término "evidencia" refuerza una visión positivista de la misma realidad y de las formas de mostrar su funcionamiento, la cual queda reflejada en estos datos. El problema estaría, entonces, no en que se quiera producir conocimiento con evidencias, sino en lo que se entiende por evidencia. 
a las personas o a las instituciones responsables de su desempeño y que, por tanto, constituyen un sistema de evaluación basado en la rendición de cuentas. Explica este autor que hay cuatro grandes teorías que sustentan la evaluación basada en la rendición de cuentas: a) La teoría de la motivación, la cual argumenta que la evaluación basada en la rendición de cuentas puede motivar la mejora. Para esta teoría, las evaluaciones orientadas a la rendición de cuentas se basan en la creencia de que fijar incentivos - positivos o negativos- mejora el rendimiento de estudiantes y de docentes; así, por ejemplo, desde esta creencia la Organización para la Cooperación y Desarrollo Económicos (OECD, 2013) recomienda la introducción de evaluaciones con consecuencias de alto riesgo para los estudiantes. b) La teoría de la alineación, según la cual las evaluaciones basadas en la rendición de cuentas desempeñan un papel importante en la alineación, homogeneización o estandarización de los principales componentes del sistema educativo. Desde este punto de vista, Tröhler (2009) observa el Programme for International Student Assessment (PISA) como un instrumento de gobernanza mundial para la "armonización" educativa a nivel global. c) La teoría de la información, la cual sostiene que los sistemas de evaluación basados en la rendición de cuentas pueden ofrecer información importante a los educadores para la mejora de sus prácticas. Desde esta perspectiva, se considera que dicha información cumple diversas funciones según quien sea el destinatario: educadores, familias, estudiantes, técnicos-políticos. d) Finalmente, en otras teorías se sostiene que un sistema de rendición de cuentas indica valores importantes para los interesados. Desde esta visión, Airasian (1988; citado por Supovitz, 2009: p. 215. Traducción propia) señala que los programas de las evaluaciones de alto impacto "simbolizan orden y control, resultados educativos deseados, y valores morales tradicionales". En la última reforma educativa española, la LOMCE de 2013, estos cuatro enfoques de la evaluación se entremezclan en lo que Ball (2001) denominaría un "proceso de bricolaje" en el que el decisor político toma ideas o retazos desde cualquier lugar, adaptando elementos al contexto local.

En cualquier caso, los efectos pedagógicos de estas políticas han sido objeto de variadas críticas. Stobart (2010) y Supovitz (2009) entienden que las mejoras en educación basadas en una relación directa entre evaluaciones y rendición de cuentas son siempre superficiales y de corta duración. Según Stobart (2010: p. 136) "las medidas" aplicadas al ámbito educativo "terminan distorsionando lo que ocurre". De acuerdo con la Ley de Goodhart "cuando una medida se convierte en objetivo, deja de ser una buena medida" (Charles Goodhart, citado por Stobart 2010: p. 135), a lo cual podemos agregar que deja de ser un buen objetivo. En consecuencia, si la rendición de cuentas y las evaluaciones se alían de esta manera, las evaluaciones quedan alejadas de cualquier posibi- 
lidad formativa y de conocimiento de la realidad evaluada y, por otra parte, suelen terminar alterando los sentidos y las prácticas educativas de diversas maneras. Por ello, de acuerdo con el análisis realizado de la bibliografía (Ball, 2003, 2013; Fernández-González, 2015; Luengo \& Saura, 2013; McDonnell, 1994; Monarca, 2012, 2015; Pérez \& Soto, 2011; Stobart, 2010; Supovitz, 2009; Whitty, Power \& Halpin, 1999), es posible referir varias consecuencias que tiene para la educación el entendimiento de la rendición de cuentas asociada a evaluaciones externas:

i) Un primer grupo de críticas alude a las consecuencias de estas políticas de rendición de cuentas sobre la subjetividad de docentes, familias y estudiantes (Jódar \& Gómez, 2007). Los sujetos son presionados para alinear su conducta con los criterios externos establecidos por las evaluaciones (Popkewitz, 2013). La profesionalidad del docente queda determinada por su capacidad para mejorar el rendimiento en esas evaluaciones y, en consecuencia, centran en ello sus tareas; quedando limitada la posibilidad de reflexión sobre los contenidos curriculares y, en términos más amplios, sobre lo que pasa en el aula. ${ }^{3}$

En relación a las familias, estas políticas educativas de rendición de cuentas refuerzan la lógica proveedor-cliente. Biesta (2004) entiende que el discurso de la rendición de cuentas codifica de una manera más mercantil la relación entre familias y escuelas. A ello contribuye la manera en que accountability se combina con choice (elección), otra palabra clave del mismo discurso, naturalizando así una democracia de consumo, donde el ciudadano es principalmente un consumidor. Whitty, Power \& Halpin (1999), en un amplio estudio comparado sobre las políticas de descentralización que daban mayor protagonismo al nivel local en Inglaterra, Gales, Estados Unidos, Australia y Nueva Zelanda, observaron que el fomento de la participación de las familias se comprendía desde este prisma mercantil. En la relación entre escuelas y familias, estas entienden la rendición de cuentas como una exigencia de calidad y de resultados que les deben las escuelas por los "servicios" que adquieren para sus hijas e hijos en esas instituciones escolares frente a otras que podrían haber elegido. En esta lógica, las evaluaciones externas contribuyen a otorgar un valor que hace atractiva una determinada elección (Monarca, Fernández-González \& Sandoval, 2015).

3 Es conveniente aclarar que, en realidad, muchos de los que defienden esta forma de implementar las evaluaciones, dan por hecho que la calidad de la educación se mide a través de los resultados en los exámenes. Por tanto, se asume que dichos exámenes representan en sí la calidad del sistema. 
ii) Un segundo grupo de críticas centran su atención en las consecuencias de estas políticas sobre la organización escolar. La introducción de la gestión empresarial en la escuela configura al director como un director-gerente (Merchán, 2012), de tal manera que el supuesto fomento de autonomía escolar es en lo hechos mayor autonomía del equipo directivo (Monarca, Fernández-González \& Sandoval, 2015). La organización se vuelve más piramidal hasta el punto incluso de modelar el estatuto laboral del profesorado, lo que precariza y proletariza su situación, caminando así hacia una organización menos democrática (Rodríguez, 2014). El Estado evaluador que implementa estas políticas presta menos atención a las medidas de carácter más pedagógico, y ve en cada escuela una empresa (Biesta, 2004), una unidad administrativa más, que debe ser eficaz y eficiente para justificar su razón de ser (Laval \& Dardot, 2013).

Por otro lado, la relación crecientemente mercantil con las familias en el contexto competitivo de cuasi mercado entre escuelas, fomenta que estas se concentren en gestionar su imagen para captar mayor clientela. De este modo, las estrategias de marketing entran dentro de la escuela y surgen así nuevas fabricaciones: otras versiones de la escuela para adaptarse a las exigencias de competitividad, preponderantemente a través de la gestión de su imagen (Ball, 2013). Esto genera una paradójica situación en la que "los proveedores mejor situados en el mercado pueden optar preferentemente por estrategias de distinción y diferenciación de producto destinado a determinados segmentos de demanda" (Bonal \& Verger, 2012: pp. 24-25). Joel Windle (2009), en su estudio sobre las prácticas de rendición de cuentas en el mercado educativo local del norte de Melbourne, observó que las escuelas de élite terminan compitiendo por fabricar esa imagen de calidad más que por captar alumnado. Asistimos de esta forma a una situación irónica, donde la cultura del rendimiento instaurada por estas prácticas de accountability disminuye la eficiencia en lugar de aumentarla dado que canaliza los esfuerzos hacia la mejora de la imagen (Ball, 2013).

La implementación de estas políticas suele llevar aparejada la financiación escolar en función de la matriculación de estudiantes, lo que desencadena una espiral de decadencia y desigualdad, fruto de la diferencia de matriculación, y consecuentemente de financiación. Este es uno de los efectos que más se asocia a las políticas de libertad de elección, las cuales se desarrollan en estrecha vinculación con los mecanismos de rendición de cuentas y evaluaciones externas (Prieto \& Villamor, 2012).

iii) En tercer lugar, se puede entender que estas políticas colaboran a reconfigurar los sentidos en torno a la educación (Monarca, Fernández-González 
\& Sandoval, 2015). Estas evaluaciones afectan a lo que pasa en el aula: los tiempos, los contenidos y las formas de enseñanza se modifican para adaptarse a las exigencias del examen. La dedicación al entrenamiento para la prueba es cada vez mayor. En este escenario, todo lo que no es medido ni medible, lo que no es "accountable", pierde valor. Es por esto que la rendición de cuentas conduce crecientemente a "una cultura de rendimiento, en vez de al enriquecimiento de oportunidades de aprendizaje" (Whitty, Power \& Halpin, 1999: p. 114) caminando así hacia sistemas más pobres y estrechos en los que es prácticamente imposible la formación de personas flexibles y creativas (Torrance, 2011).

Desde una perspectiva macro, la tendencia al alineamiento de los currículos nacionales en una línea mercantilista de la educación está operando principalmente a través de la prueba PISA y el discurso educativo que esta porta (Fernández-González, 2015; Pedró, 2012; Tröhler, 2009). Estas políticas de evaluaciones externas y rendición de cuentas están estrechamente unidas a una comprensión neoliberal de la educación como una capitalización permanente del individuo. El sujeto debe ser lo suficientemente responsable como para ver en su educación una necesaria inversión si quiere ser un buen empresario de sí mismo.

\section{La rendición de cuentas como una práctica democrática}

De acuerdo con lo dicho, el discurso de rendición de cuentas constituye primordialmente un discurso de poder que, entre otras cosas, legitima nuevas formas de producir conocimiento e instala nuevas tecnologías de gobierno para el control de los individuos con el objetivo de responsabilizarlos por sus resultados, de constituirlos como empresarios de sí mismos. Es así como efectivamente opera la gubernamentalidad neoliberal descrita por Foucault (2007). Los efectos pedagógicos de la introducción en educación de las políticas de rendición de cuentas están lejos de contribuir a una mejora educativa: colaboran a su empobrecimiento, a una mayor desigualdad, a una organización escolar menos democrática y a la precarización del profesorado. Sin embargo, a pesar de estas consecuencias y de la ambigüedad del término accountability, la mayoría de las personas consideran que se trata de algo bueno, de un objetivo intrínsecamente deseable (Charlton, 2002; Poulson, 1998). Teniendo en cuenta eso, ¿cuál es la causa de esta aceptación generalizada? ¿Y cómo es posible tal aceptación sobre un término tan indeterminado?

Charlton (2002) entiende que existen dos definiciones de rendición de cuentas: una técnica, propia del discurso de la gestión, que se refiere "a la obligación de 
presentar cuentas auditables", y una segunda que tiene un sentido casi opuesto al anterior, que se asocia a valores democráticos, igualitarios, radicales y de "empoderamiento". McDonnell (1994) establece una clasificación similar. Considera que hay dos modelos de rendición de cuentas, uno profesional y otro político. Con respecto al político, explica el autor, se sostiene en una definición participativa del interés común, bajo el supuesto de que hay una falta de consenso sobre las metas de desarrollo social de instituciones como las escuelas. En este sentido, y desde este modelo, la política de rendición de cuentas se ha definido como un conjunto de valores de un procedimiento diseńado para garantizar un proceso justo y abierto para determinar los objetivos que deben prevalecer. Con respecto a este punto de vista, McDonnell (1994) sostiene que la responsabilidad política es esencialmente una relación recíproca en la que deben entrar los políticos, el profesorado y la comunidad en general. En su máxima expresión, el modelo político de rendición de cuentas supone una aceptación compartida de la responsabilidad entre escuelas y comunidad en general. Por otra parte, explica McDonell, el modelo profesional se basa en otros supuestos: un grupo de expertos determina los aspectos que deben ser regulados y toma decisiones sobre ellos, sin la intervención de una instancia política externa. Los juicios se basan en evaluaciones con criterios cuantitativamente muy claros, no en juicios políticos.

Tanto el modelo político de rendición de cuentas que describe McDonnell (1994) como la definición en un sentido democratizador de Charlton (2002) parecen estar en línea con el espíritu que subyace al concepto de rendición de cuentas ofrecido en la política comparada, un área que Hopmann (2008) no incluye en su revisión. Desde esta disciplina, los esfuerzos por conceptualizar la rendición de cuentas y por buscar y clasificar las maneras de instrumentalizarla derivan de la preocupación sobre los límites del poder: "cómo mantener el poder bajo control, cómo domesticarlo, cómo prevenir sus abusos, cómo supeditarlo a ciertos procedimientos y reglas de conducta" (Schedler, 2008: p. 9). Conviene recordar que los límites del poder y del gobierno ha sido un tema recurrente en toda la historia del pensamiento político desde Platón y Aristóteles. En las democracias representativas actuales, o poliarquías ${ }^{4}$ (Dahl, 1992), la idea de rendición de cuentas cobra sentido ante la constatación de una brecha entre representantes y representados, una brecha connatural a la idea de representación. En este escenario, los mecanismos de accountability buscan la

4 Los atributos de una poliarquía son: 1. Cargos políticos electos, 2. Elecciones libres, periódicas e imparciales, 3. Sufragio universal, 4. Derecho a ocupar cargos públicos, 5. Libertad de expresión, 6. Canales de información alternativos y variedad de fuentes informativas protegida por ley, 7. Derecho de libre asociación (Dahl, 1992). 
manera de regular y reducir esta brecha "preservando siempre la distancia entre autoridades políticas y ciudadanía que caracteriza a las relaciones de representación" (Peruzzotti \& Smulovitz, 2002: p. 25). Es importante destacar que la accountability no cuestiona la noción de representación, de la misma manera que tampoco intenta eliminar el poder. Asume el poder como una realidad cierta e intenta minimizar sus abusos procurando las maneras de controlarlo (Schedler, 2008).

Andreas Schedler (2008) entiende que la rendición de cuentas tiene tres dimensiones básicas: informativa, justificativa y de castigo. En virtud de las dos primeras dimensiones, el poder debe abrirse a la luz pública y explicar racionalmente el porqué de sus actos. Esto incluye un aspecto narrativo donde el gobierno relate y justifique sus decisiones, $\mathrm{y}$ un aspecto contable donde dé cuenta de la buena gestión de los recursos públicos, aspecto vinculado al objetivo de eficiencia. La dimensión sancionadora no siempre está presente: por ejemplo, en lo que Peruzzotti \& Smulovitz (2002) catalogan como accountability social, la sanción no es un requisito. En el caso de la rendición de cuentas de políticos, muchas veces la sanción es la remoción de su cargo o la exposición pública de sus malas conductas. En casos en que el comportamiento incurra en ilícito civil, administrativo o penal, y exista castigo judicial, no cabe duda de la existencia de sanción (Schedler, 2008). Ackerman (2004) incluye otra dimensión más: la receptividad del gobierno a las opiniones y preferencias de los ciudadanos. Sin embargo, no es necesario que todas estas dimensiones estén presentes: "Al igual que el pastel de cumpleaños que reconocemos como pastel aunque le falte una rebanada, reconocemos prácticas de rendición de cuentas como tales aunque les falte una de sus tres 'rebanadas' constitutivas" (Schedler, 2008: p. 23).

En atención a la dirección en que se articulan los mecanismos de accountability, es clásica la distinción de Guillermo O’Donnell (1997) entre accountability vertical y horizontal. La rendición de cuentas vertical es la que se establece entre ciudadanía y representantes y se articula sobre todo a través de las elecciones. La accountability social de la que hablan Peruzzotti \& Smulovitz (2002) es otro mecanismo de control vertical a través del cual, asociaciones, movimientos sociales u organizaciones no gubernamentales (ONG) exponen y denuncian actos de las autoridades públicas mediante acciones mediáticas. Esta rendición de cuentas social se caracteriza por ser intensiva, ya que, a diferencia de las elecciones, no tiene que aunar a gran parte de la ciudadanía, sino que debe conseguir ser intensa y mediática. Su capacidad sancionadora varía: puede dar lugar a un procedimiento judicial cuando denuncie ilícitos, o puede simplemente denunciar una conducta inadecuada. Fox (2006) de igual forma entiende que existen mecanismos de rendición de cuentas vertical inversa ya que los ciudadanos son sujetos de derechos pero también de deberes, y esos deberes constituyen la razón 
por la que gobiernos exigen cuentas a la ciudadanía, aunque es posible que en ocasiones el poder se extralimite en la exigencia de cuentas ciudadana.

La rendición de cuentas horizontal es la existencia de agencias intraestatales habilitadas por ley, capacitadas y dispuestas en los hechos, para "emprender acciones que abarcan desde la fiscalización rutinaria hasta sanciones penales o destitución, en relación con actos u omisiones de otras instituciones del Estado que puedan calificarse, en principio o presuntamente, como ilícitos" (O’Donnell, 1997: p. 13). La institucionalización de la división y el balance de poderes en el Estado constituyen mecanismos clásicos de accountability horizontal (O'Donnell, 2004). Por otro lado, los criterios o principios normativos desde los que se cumple esa tarea de control del poder son múltiples y varían en función del subsistema político al que nos refiramos: podemos hablar de criterios políticos, administrativos, profesionales, financieros, legales, constitucionales e incluso morales, y además estos principios pueden entrar en conflicto (Schedler, 2008). A tenor de lo expuesto, el concepto de rendición de cuentas se caracteriza por su amplitud y su carácter multifacético (Schedler, 2008). En un esfuerzo por intentar aprehender el núcleo esencial de la accountability, podemos conformarnos con la idea de que incluye tres tipos de procesos: "la participación ciudadana en la definición de políticas públicas, el seguimiento o monitoreo de esas políticas públicas y la evaluación o balance del resultado de las mismas", procesos bastante amplios, en cualquier caso (Olvera \& Isunza, 2004: p. 341).

\section{La rendición de cuentas: un significante a llenar}

La ambigüedad del concepto de rendición de cuentas no ha sido obstáculo para su protagonismo en los discursos políticos. Olvera \& Isunza (2004) entienden que la noción de accountability ha cobrado relevancia desde la década de los noventa por la confluencia de tres procesos. En primer lugar, la transición en muchos países a democracias electorales en el marco de lo que se denominó "la tercera ola de democratización" (Huntington, 1994) y el sucesivo reconocimiento de su insuficiencia para evitar "la vieja lógica del secretismo burocrático, del clientelismo, de la corrupción y de los arreglos privados de asuntos públicos" (Olvera \& Isunza, 2004: p. 337). Ante esto, parece constatarse la necesidad de una sociedad civil activa que ejerza presiones sociales desde abajo. En segundo lugar, y en el nivel internacional, las agencias internacionales de desarrollo comenzaron a preocuparse por la transparencia gubernamental mientras que los Estados donantes exigían mejor eficacia en la gestión de los fondos internacionales. Paralelamente, la internacionalización de movimientos sociales feministas y ecologistas, y de grupos de derechos humanos, participa- 
ron de esta exigencia de transparencia, pero sobre todo de una mayor participación civil en los procesos de políticas públicas. En tercer lugar, Olvera \& Isunza (2004) aluden a la influencia, al menos en América Latina, de la nueva gestión pública: la necesidad de una reforma administrativa para hacer al Estado más eficiente y más permeable a las demandas ciudadanas, y la organización de la administración pública de acuerdo a principios traídos del mundo empresarial. En este contexto, la apelación a la participación ciudadana y a la sociedad civil cobra nuevo empuje; posteriormente, de igual modo, la noción de accountability.

En la complejidad de estos procesos, todas estas palabras son usadas como parte de proyectos políticos divergentes, lo que Dagnino (2006) cataloga como una confluencia perversa. Ella observa que en el caso brasileño se dieron dos proyectos divergentes. Por un lado, un proyecto democratizante, dentro del cual son claves el restablecimiento de elecciones democráticas libres, la reorganización del sistema de partidos y el paso, durante los noventa, a una acción conjunta entre la sociedad civil y el Estado tras décadas de antagonismo. Este proyecto pretendía una profundización de la democracia participativa, lo que se plasmó en el principio de participación consignado en la constitución brasileña de 1988, y en experiencias como la elaboración de presupuestos participativos en más de cien ciudades o en los Consejos Gestores de Políticas Públicas con representación proporcional del Estado y la sociedad civil. Por otro lado, y como parte de su hegemonía a nivel global, el proyecto neoliberal entra de la mano del presidente Collor de Mello en 1989, y de los discursos de ajuste estructural de las agencias internacionales. Para Dagnino, la perversidad de esta confluencia "se revela precisamente en el hecho de que, apuntando hacia direcciones opuestas y antagónicas, ambos proyectos requieren una sociedad civil activa y propositiva" (Dagnino, 2006: p. 225). La autora analiza cómo el proyecto neoliberal llenó los significantes participación, sociedad civil y ciudadanía en un sentido más individualista, conectando la ciudadanía al mercado. Incluso la idea de solidaridad quedó enmarcada en el territorio privado e individual de la moral, vinculado a las necesidades de pobreza y equiparado a la caridad. Se trató de un proyecto de despolitización de todos estos conceptos que elimina los espacios públicos de solidaridad y de participación, y abordó estas ideas desde perspectivas de gestión técnica o tratándolas como áreas propias de la filantropía del tercer sector.

Esta confluencia perversa que describe Dagnino es posible gracias a lo que en términos laclaunianos es un vaciamiento del significante. Un significante vacío no tiene un significado concreto, sino que simplemente construye una dicotomía radical entre lo bueno y lo malo: todo lo que queda referido dentro del significante es el bien y lo que deja fuera es el mal. En este sentido, partici- 
pación, sociedad civil y ciudadanía, al igual que rendición de cuentas inspiran lo bueno, expresan los valores de la comunidad, lo puramente positivo y el bien. Mientras que todo aquello que no queda significado dentro de estos conceptos encarna "la anticomunidad, pura negatividad y el mal" (Laclau, 1996: pp. 7980). En el caso de accountability, Olvera \& Isunza (2004) explican que este discurso emerge en un contexto de desencanto y frustración frente a la opacidad, ineficiencia e incapacidad de los gobiernos de reformarse a sí mismos y de abrirse a la luz pública. En tanto que significante vacío, rendición de cuentas alude a una plenitud ausente en ese escenario, un vacío deseable: transparencia, publicidad y balance público de la acción estatal. Entendiendo la rendición de cuentas como un significante vacío que expresa los valores comunitarios en situaciones de insatisfacción ciudadana, se comprende su gran aceptación, independientemente de las medidas políticas que al amparo de ese significante se desplieguen. A este respecto, también España, donde en los últimos años han salido a la luz pública innumerables casos de corrupción política que afectan a altos cargos de los dos partidos más importantes —aunque con mayor intensidad al Partido Popular-, es un terreno propicio para articular un discurso sobre el control del poder político bajo el significante de rendición de cuentas.

Algunas consecuencias de este vaciamiento son que, aunque se hable de accountability con un sentido más técnico y gerencialista, automáticamente se asocia a su definición más democrática de control del poder. Esto es lo que Charlton (2002) denomina un "quick switch", un interruptor, entre la noción más gerencialista que ha inspirado, por ejemplo, las políticas educativas de accountability y una noción democratizante. Una segunda consecuencia es la dificultad para argumentar en contra de la rendición de cuentas, ya que cualquiera que lo haga será rápidamente tachado de irresponsable (Biesta, 2004). Por otro lado, ante un significante vacío, "varias fuerzas pueden competir en su esfuerzo por presentar sus objetivos particulares como aquellos que llenan ese vacío" (Laclau, 1996: p. 84). Esto es lo que convierte a un significante vacío en significante flotante. Explica Laclau (2005) que la diferencia entre uno y otro es estructural: en los significantes flotantes ya se ha aprehendido la lógica de los significantes vacíos y se emplea conscientemente para provocar los desplazamientos en la frontera entre lo que queda dentro y lo que queda fuera del significante. Es por esto que proyectos políticos muy diferentes pueden apelar a mismos conceptos.

En materia educativa, la rendición de cuentas se instrumenta de modo fundamental a través de mecanismos verticales inversos, es decir, mecanismos por medio de los cuales la ciudadanía es controlada por el poder (Fox, 2006), con las consecuencias pedagógicas que previamente se han apuntado. Esta confusión trasciende además el área de las políticas educativas. El papel protagonista de 
la gestión (management) en los ámbitos de políticas públicas —en educación, salud y gobierno local— conduce, como ya apuntamos, a una colonización de sus prácticas propias (Fairclough, 2000). El hecho de que decisores políticos, cuando hablan de rendición de cuentas, piensen sobre todo en una práctica para el control de los agentes y del individuo, en vez de una práctica para controlar su propia conducta, es una manifestación de esta colonización, estrechamente vinculada con la racionalidad neoliberal que impera en el momento actual.

Otro aspecto de esta disputa simbólica se relaciona con los criterios o principios normativos desde los que rendir cuentas. Como se ha mencionado arriba, existe multitud de criterios, los cuales pueden entrar en conflicto. En materia educativa, es común que se hable de evidencias obtenidas mediante estos mecanismos de rendición de cuentas. Estas evidencias asumen de manera positivista que la calidad educativa se mide cuantitativamente con las evaluaciones externas y que esos exámenes representan la calidad educativa del sistema. Estos exámenes, que constituyen un mecanismo de accountability vertical inverso, portan ya criterios normativos impuestos por expertos y decisores políticos, criterios que no han sido explícitamente discutidos en la arena política. Con estas evaluaciones se pretende eludir una discusión de carácter ideológico sobre qué entender por calidad, y más profundamente, cuáles son los fines de la educación. De nuevo, como Dagnino (2006) observaba en el caso brasileño, el proyecto neoliberal pretende despolitizar conceptos reconduciéndolos a marcos puramente técnicos.

\section{A modo de conclusión}

Ante la ambigüedad del concepto accountability, parece que el proyecto neoliberal ha ganado la batalla por llenar su significado. A pesar de ello, y a pesar de las consecuencias negativas que provoca sobre la calidad de la educación, el término sigue gozando de gran aceptación entre la ciudadanía. En escenarios de desencanto ciudadano e indignación frente a los escándalos de corrupción política - muy especialmente en España — es comprensible que la rendición de cuentas política goce de aceptación, ya que evoca la necesidad de controlar al poder para evitar sus abusos. De hecho, esta es la preocupación principal en el área de la política comparada que trabaja sobre este concepto. Sin embargo, las políticas implementadas al amparo de este concepto se inspiran más en teorías propias de la gestión cuyo objeto es el control del individuo, en concordancia con la racionalidad neoliberal imperante (Laval \& Dardot, 2013).

Dagnino (2006) explicaba cómo en Brasil los términos de sociedad civil, participación, solidaridad o ciudadanía, fueron objeto de una pugna por su sig- 
nificado en una disputa entre el proyecto neoliberal y el democratizante. En esta pugna, "las oscilaciones semánticas o las dislocaciones de significado son las armas principales" (Dagnino, 2006: p. 225). Un fenómeno similar ha pasado con el término commons (comunes, en español). Lo común ha sido el eje vertebrador de las luchas anticapitalistas globales en las últimas décadas (Laval \& Dardot, 2015). Sin embargo, el término, asimismo, ha sido objeto de apropiación neoliberal desde los sesenta con la paradójica intención de reforzar los derechos de propiedad privada (Blackmar, 2006). Estos ejemplos ilustran la tesis de que no hay ningún término taumatúrgico, ninguna palabra llave que sea en sí misma una solución. Cada significante siempre es llenado por un proyecto político que necesariamente es ideológico. Pretender que la solución es técnica y está encerrada en una palabra, significa sustraer la actividad política a la ciudadanía. Es una manera de clausurar el sentido de las instituciones existentes, de impedir el cuestionamiento de sus fines, lo que es más propio de regímenes no democráticos donde no se permite que la política sea una actividad lúcida y explícita (Castoriadis, 2001).

\section{Referencias}

Ackerman, J. (2004). Sinergia Estado-Sociedad en pro de la rendición de cuentas: Lecciones para el Banco Mundial. Documento de Trabajo del Banco Mundial, (31). Recuperado el 18 de septiembre de 2017, de http://documentos.bancomundial.org/curated/es/521481468762605158/ pdf/29701.pdf

Ball, S. (2015). Prólogo. En Monarca, H. (Ed.). Evaluaciones externas. Mecanismos para la configuración de representaciones y prácticas en educación (pp. 13-16). Buenos Aires: Miño y Dávila.

Ball, S. (2013). Performatividad y fabricaciones en la economía educacional: rumbo a una sociedad performativa. Pedagogía y Saberes, (38), 103-113.

Ball, S. (2003). Profesionalismo, gerencialismo y performatividad. Revista Educación y Pedagogía, $X V(37), 87-104$.

Ball, S. (2001). Global Policies and Vernacular Politics in Education. Curriculo sem Fronteiras, $1(2), 26-43$.

Ball, S. \& Youdell, D. (2007). Privatización encubierta en la educación pública. Informe preliminar para el $V$ Congreso Mundial de la Internacional de la Educación. Londres: Instituto de Educación-Universidad de Londres. 
Barroso, J. (2005). O estado, a educação e a regulação das políticas públicas. Educação e Sociedade, 26(92), 725-751.

Biesta, G. (2004). Education, Accountability and the Ethical Demand: Can the Democratic Potential of Accountability be Regained? Educational Theory, 54(3), 233-250.

Blackmar, E. (2006). Appropiating "the Commons": The Tragedy of Property Rights Discourse. En Low, S. \& Smith, N. (Eds.). The Politcs in Public Space (pp. 49-80). Nueva York: Routledge.

Bonal, X. \& Verger, A. (2012). La emergencia de las alianzas públicoprivado en la agenda educativa global: Nuevos retos para la investigación educativa. Profesorado. Revista de Currículum y Formación del Profesorado, 16(3), 11-29.

Burchardt, H.-J. (2004). El nuevo combate internacional contra la pobreza. Nueva Sociedad, (193), 119-132.

Carvalho, L. M. (2009). Governando a educação pelo espelho do perito: uma análise do PISA como instrumento de regulação. Educação \& Sociedade, 30(109), 1009-1036.

Castoriadis, C. (2001). La democracia como procedimiento y como régimen. Realidad: Revista de Ciencias Sociales y Humanidades, (83), 593-610.

Cerny, P. (1997). Paradoxes of the Competition State: the Dynamic of Political Globalization. Government and Opposition, 32(2), 251-271.

Charlton, B. (2002). Audit, Accountability, Quality and All That: The Growth of Managerial Technologies in UK Universities. En Prickett, S. \& Erskine-Hill, P. (Eds.). Education! Education! Education! Managerial Ethics and the Law of Unintended Consequences (pp. 13-28). Thorverton: Imprint Academic.

Comisión Europea (2001). La gobernanza europea-Un Libro Blanco. Recuperado el 18 de septiembre de 2017, de http://eur-lex.europa.eu/legal-content/ES/TXT/?uri=celex:52001DC0428

Da Silva, T. (1997). Descolonizar el currículo: estrategias para una pedagogía crítica (Dos o tres comentarios sobre el texto de Michael Apple). En Gentili, P. (Comp.). Cultura, politica y currículo (pp. 63-78). Buenos Aires: Losada.

Dagnino, E. (2006). Sociedad civil, participación y ciudadanía, ¿de qué estamos hablando? En Isunza, E. \& Olvera, A. (Coords.). Democratización, rendición de cuentas y sociedad civil: participación ciudadana y control social (pp. 223-242). México: Centro de Investigaciones y Estudios Superiores en Antropología Social/Universidad Veracruzana/Miguel Ángel Porrúa.

Dahl, R. (1992). La democracia y sus críticos. Barcelona: Paidós. 
Dale, R. (2007). Los efectos de la globalización en la política nacional: Un análisis de los mecanismos. En Bonal, X., Tarabini, A. \& Verger, A. (Comps.). Globalización y educación. Textos fundamentales (pp. 87-114). Buenos Aires: Miño y Dávila.

Dale, R. (1999). Specifying Globalization Effects on National Policy: A Focus on the Mechanisms. Journal of Education Policy, 14(1), 1-17.

Deleuze, G. (2006). Post-scriptum sobre las sociedades de control. Polis. Revista de la Universidad Bolivariana, 5(13). Recuperado el 18 de septiembre de 2017, de http://www.redalyc.org/ articulo.oa?id=30551320

Domingues, J. M. (2014). Social liberalismo y dominación global. Geopolítica(s), 4(2), 183-198.

Fairclough, N. (2000). Representaciones del cambio en el discurso neoliberal. Cuaderno de Relaciones Laborales, (16), 13-35.

Fernández-González, N. (2015). PISA como instrumento de legitimación de la reforma de la LOMCE. Bordón. Revista de Pedagogía, 67(1): 165-178.

Fraser, N. (2003). From Discipline to Flexibilization. Constellations, 10(2), 160-171.

Foucault, M. (2007). Nacimiento de la biopolitica. Buenos Aires: Fondo de Cultura Económica.

Fox, J. (2006). Sociedad civil y políticas de rendición de cuentas. Perfiles Latinoamericanos, 13(27): 33-68.

Giddens, A. (1999). La tercera vía: La renovación de la socialdemocracia. Madrid: Taurus.

Grek, S. (2009). Governing by numbers: the PISA "effect" in Europe. Journal of Education Policy, 24(1), 23-37.

Hargreaves, A. (1996). Profesorado, cultura y postmodernidad. Madrid: Morata.

Hopmann, S. T. (2008). No Child, no School, no State Left Behind: Schooling in the Age of Accountability. Journal of Curriculum Studies, 40(4), 417-456.

Huntington, S. (1994). La tercera ola: la democratización a finales del siglo XX. Barcelona: Paidós.

Jódar, F. \& Gómez, L. (2007). Educación posdisciplinaria, formación de nuevas subjetividades y gubernamentalidad neoliberal. Revista Mexicana de Investigaciones Educativas, 12(32), 381-404.

Laclau, E. (2005). La razón populista. Buenos Aires: Fondo de Cultura Económica. 
Laclau, E. (1996). Emancipación y diferencia. Buenos Aires: Ariel.

Laval, C. \& Dardot, P. (2015). Común. Ensayo sobre la revolución en el siglo XXI. Barcelona: Gedisa.

Laval, C. \& Dardot, P. (2013). La nueva razón del mundo. Barcelona: Gedisa.

Luengo, J. \& Saura, G. (2013). La performatividad en la educación. La construcción del nuevo docente performativo y el nuevo gestor performativo. Revista Iberoamericana sobre Calidad, Eficacia y Cambio en Educación, 11(3), 139-153.

Mausethagen, S. (2013). Accountable for What and to Whom? Changing Representations and a New Legitimation of Discourses Among Teachers Under Increased External Control. Journal of Education Change, 14(4), 423-444.

McDonnell, L. (1994). Assessment Policy as Persuasion and Regulation. American Journal of Education, 102(4), 394-420.

Merchán, F. J. (2012). La introducción en España de la política educativa basada en la gestión empresarial de la escuela: el caso de Andalucía. Archivos Analiticos de Politicas Educativas, 20(32), 1-28.

Monarca, H. (2015). Sistemas de evaluación: disputas simbólicas y configuración de prácticas educativas en los procesos de globalización y reforma del Estado. En Monarca, H. (Ed.). Evaluaciones externas. Mecanismos para la configuración de representaciones y prácticas en educación (pp. 17-42). Buenos Aires: Miño y Dávila.

Monarca, H. (2012). La influencia de los sistemas nacionales de evaluación en el desarrollo del currículo. Perfiles Educativos, 34(135), 164-176.

Monarca, H., Fernández-González, N. \& Sandoval, N. (2015). Reconfiguración de los sentidos sobre la educación en España a partir de la nueva ley de educación (LOMCE). En Monarca, H. (Ed.). Evaluaciones externas. Mecanismos para la configuración de representaciones y prácticas en educación (pp. 173-190). Buenos Aires: Miño y Dávila.

Neave, G. (1988). On the Cultivation of Quality, Efficiency and Enterprise: and Overview of Recent Trends in Higher Education in Western Europe, 1986, 1988. European Journal of Education, 3(1-2), 7-17.

O’Donnell, G. (2004). Accountability horizontal: la institucionalización legal de la desconfianza. Revista Española de Ciencia Política, (11), 11-31.

O’Donnell, G. (1997). Rendición de cuentas horizontal y nuevas poliarquías. Nueva Sociedad, (158), 143-167. 
O’Neill, O. (2013). Intelligent Accountability in Education. Oxford Review of Education, 39(1), 4-16.

Olvera, A. \& Isunza, E. (2004). Rendición de cuentas: Los fundamentos teóricos de una práctica de la ciudadanía. En Ziccardi, A. (Coord.). Participación ciudadana y políticas sociales del ámbito local (pp. 335-358). México: Instituto Nacional de Desarrollo Social.

Ong, A. (2007). Neoliberalism as a Mobile Technology. Transactions of the Institute of British Geographers, 32(1), 3-8.

Organisation for Economic Co-operation and Developmen (OECD) (2013). PISA 2012 results: What Makes Schools Successful? Resources, Policies and Practices (volume IV). OECD Publishing.

Pedró, F. (2012). Deconstruyendo los puentes de PISA: Del análisis de resultados a la prescripción política. Revista Española de Educación Comparada, (19), 139-172.

Pérez, Á. \& Soto, E. (2011). Luces y sombras de PISA. Sentido educativo de las evaluaciones externas. Cultura y Educación: Revista de Teoría, Investigación y Práctica, 23(2), 171-182.

Peruzzotti, E. \& Smulovitz, C. (2002). Accountability social: la otra cara del control. En Peruzzotti, E. (Coord.). Controlando la política. Ciudadanos y medios en las nuevas democracias latinoamericanas (pp. 23-53). Buenos Aires: Temas.

Popkewitz, T. (2013). PISA: números, estandarización de la conducta y la alquimia de las materias escolares. Profesorado. Revista de Currículum y Formación de Profesorado, 17(2), 47-64.

Poulson, L. (1998). Accountability, Teacher Professionalism and Education Reform in England. Teacher Development, 2(3), 419-432.

Prieto, M. \& Villamor, P. (2012). Libertad de elección, competencia y calidad: las políticas educativas de la Comunidad de Madrid. Profesorado. Revista de Currículum y Formación de Profesorado, 16(3), 127-144.

Puelles, M. (2009). Calidad, reformas escolares y equidad social. En Santos Rego, M. (Ed.). Politicas educativas y compromiso social el progreso de la equidad y la calidad (pp. 25-39). Barcelona: Octaedro.

Robertson, S., Bonal, X., \& Dale, R. (2007). El AGCs y la industria de los servicios educativos. En Bonal, X., Tarabini, A. \& Verger, A. (Comps.). Globalización y Educación (pp. 205-232). Buenos Aires: Miño y Dávila. 
Rodríguez, C. (2014). La proletarización del profesorado en la LOMCE y en las nuevas políticas educativas: de actores a culpables. Revista Interuniversitaria de Formación del Profesorado, 28(3), 73-87.

Schedler, A. (2008). Qué es la rendición de cuentas. Cuadernos de Transparencia. México: Instituto Federal de Acceso a la Información. Recuperado el 18 de septiembre de 2017, de http:// inicio.ifai.org.mx/Publicaciones/Cuadernillo\%2003\%20B.pdf

Stobart, G. (2010). Tiempos de pruebas: Los usos y abusos de la evaluación. Madrid: Morata.

Supovitz, J. (2009). Can High Stakes Testing Leverage Educational Improvement? Prospects from the Last Decade of Testing and Accountability Reform. Journal of Educational Change, (10), 211-227.

Torrance, H. (2011). Using Assessment to Drive the Reform of Schooling: Time to Stop Pursuing the Chimera? British Journal of Educational Studies, 59(4), 459-485.

Tröhler, D. (2009). Armonizar el globo educativo. Política mundial, rasgos culturales y los desafíos investigación educativa. Profesorado. Revista de Curriculum y Formación del Profesorado, 13(2), 11-14. Recuperado el 18 de septiembre de 2017, de http://www.ugr.es/ -recfpro/ rev132FIRINV1.pdf

Whitty, G., Power, S. \& Halpin, D. (1999). La escuela, el Estado y el mercado. Madrid: Morata.

Windle, J. (2009). The Limits of School Choice: Some Implications for Accountability of Selective Practices and Positional Competition in Australian Education. Critical Studies in Education, 50(3), 231-246.

Recibido el 23 de octubre de 2015. Aceptado el 29 de septiembre de 2016. 